\title{
Sol-Gel Synthesized Semiconductor Oxides in Photocatalytic Degradation of Phenol
}

\author{
Maria K. Cherepivska and Roman V. Prihod'ko \\ Dumanskii Institute of Colloid and Water Chemistry, National Academy of Sciences of Ukraine, Kiev, Ukraine \\ Correspondence should be addressed to Maria K. Cherepivska; m.cherepivskaya@gmail.com
}

Received 28 October 2013; Accepted 20 November 2013; Published 5 January 2014

Academic Editors: P. L. Gentili and S. Sasaki

Copyright ( 2014 M. K. Cherepivska and R. V. Prihod'ko. This is an open access article distributed under the Creative Commons Attribution License, which permits unrestricted use, distribution, and reproduction in any medium, provided the original work is properly cited.

\begin{abstract}
Effectiveness of photocatalytic degradation of phenol in aqueous solution using semiconductor oxides (SO) prepared by a sol-gel method was examined. The physical and chemical properties of synthesized catalysts were investigated by X-ray diffraction (XRD), diffuse reflectance UV-Vis spectroscopy (DRS), and $\mathrm{N}_{2}$-adsorption measurements. The optimal conditions of the photocatalytic degradation of phenol using prepared titanium dioxide sample were defined.
\end{abstract}

\section{Introduction}

Heterogeneous photocatalysis on the semiconductors allows achieving complete mineralization of the various classes toxic and biorefractory organic substances $[1,2]$. Recently, the photocatalytic degradation of toxicants became one of the most promising directions of "green chemistry" [3]. The use of nanosized SO presents a great interest due to their outstanding optical, magnetic, catalytic, and sensing properties $[4,5]$. The phenolic compounds contained in the wastewater of chemical, petrochemical, and pharmaceutical industries are hazardous carcinogenic and mutagenic pollutants $[6,7]$. Furthermore, the oxidation of these substances in water bodies leads to decrease in dissolved oxygen required for normal functioning of animals and plants. Finding effective methods for the protection of water systems from phenols contamination is an important aim to ensure environmental safety $[8,9]$.

Among SO photocatalysts (PC) high activity have $\mathrm{Fe}_{2} \mathrm{O}_{3}$, $\mathrm{WO}_{3}, \mathrm{ZnO}$ and $\mathrm{TiO}_{2}$. Iron oxide polymorphs of hematite $\left(\alpha-\mathrm{Fe}_{2} \mathrm{O}_{3}\right)$ are nontoxic, cheap, and stable to photocorrosion material intensively absorbs radiation in the range from 295 to $600 \mathrm{~nm}$. The semiconductor properties of $\alpha-\mathrm{Fe}_{2} \mathrm{O}_{3}$ are the same as $\mathrm{WO}_{3}$, which can be seen in the position of band gaps relative to the standard hydrogen electrode. $\mathrm{WO}_{3}$ has chemical stability in acidic medium and electrolyte solutions as well as photoactivity in the near ultraviolet and blue regions of solar spectrum [10]. According to Daneshvar et al. nanosized $\mathrm{ZnO}$ is a suitable alternative to $\mathrm{TiO}_{2}$ due to the band gap energy. Dinda and Icli found that $\mathrm{ZnO}$ was as reactive as $\mathrm{TiO}_{2}$ for the photocatalytic degradation of phenol under concentrated sunlight [11]. Figure 1 shows a scheme of the energy levels of the studied semiconductor oxides relative to the standard hydrogen potential [12]. Several authors have associated the efficiency of semiconductor photocatalysts with electronic, structural, and morphological properties of the material such as band gap energy, crystalline structure, surface area, particle size [13].

The activity of semiconductor oxides prepared by the solgel methods was investigated under the same conditions for searching of the most effective system in the reaction of the phenol photodegradation. The optimal parameters of the phenol photodegradation on the synthesized PC were defined.

\section{Materials and Methods}

2.1. Materials. All solvents and chemicals used in this work were of analytical grade and were used without further purification. Inorganic $\left(\mathrm{Fe}\left(\mathrm{NO}_{3}\right)_{3} \cdot 9 \mathrm{H}_{2} \mathrm{O}, \mathrm{Zn}\left(\mathrm{NO}_{3}\right)_{2}\right.$, $\mathrm{Na}_{2} \mathrm{WO}_{4} \cdot 2 \mathrm{H}_{2} \mathrm{O}$ ), and organic $\left(\mathrm{Ti}(i-\mathrm{OPr})_{4}\right)$ precursors for the synthesis of oxides were purchased from Sigma-Aldrich. The homogeneous precipitant urea $\left(\mathrm{CO}\left(\mathrm{NH}_{2}\right)_{2}\right)$ and nitric acid $\left(\mathrm{HNO}_{3}\right)$ were purchased from Merck (Germany). In 


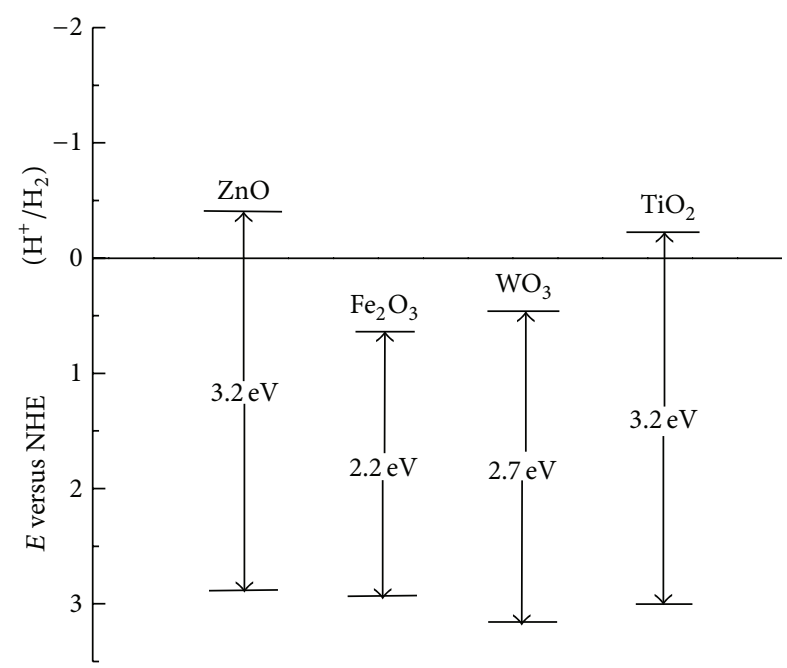

FiguRE 1: Energy band gap of investigated semiconductor oxides.

some cases the $\mathrm{pH}$ solutions were varied with $\mathrm{NaOH}$ and $\mathrm{H}_{2} \mathrm{SO}_{4}$ (Merck, Germany). P25 $\mathrm{TiO}_{2}$ was purchased from the Degussa Company in Germany and was used as the reference sample. The Millipore Q Millipore system was used for water purification.

2.2. Synthesis of Semiconductor Oxides Powders. Synthesis of PC was carried out by sol-gel method which allows obtaining nanosized metal oxide particles with desired structural and morphological properties [14].

$\mathrm{Fe}_{2} \mathrm{O}_{3}$ sample was synthesized similar to the method [15]. Solutions of $\mathrm{Fe}\left(\mathrm{NO}_{3}\right)_{3}$ and $\mathrm{CO}\left(\mathrm{NH}_{2}\right)_{2}$ were slowly added in the heated deionized water with continues stirring. The mixture was heated at $363 \mathrm{~K}$ for $5 \mathrm{~h}$ to form and aging of $\mathrm{Fe}(\mathrm{OH})_{3}$ sol. The resulting russet precipitation was dried at $383 \mathrm{~K}$ and calcined at $773 \mathrm{~K}$ for $2 \mathrm{~h}$ in the air.

$\mathrm{WO}_{3}$ sample was prepared by thermal decomposition of tungstic acid obtained by the sol-gel method [13]. In this procedure, sodium tungstate dihydrate was dissolved in deionized water under continuous stirring at $353 \mathrm{~K}$. After total dissolution, concentrated nitric acid was added dropwise to the sodium tungstate solution. The reaction mixture was subjected to the aging process during 40 minutes at $353 \mathrm{~K}$ and left for $24 \mathrm{~h}$ at $293 \mathrm{~K}$. The resulting pale yellow precipitation was filtered, washed with deionized water, dried at $353 \mathrm{~K}$, and calcined at $773 \mathrm{~K}$ during $2 \mathrm{~h}$ in the air.

Synthesis of nanocrystalline $\mathrm{ZnO}$ powder was performed similar to [16], by alkaline hydrolysis of zinc nitrate in thermoinitiated decomposition of urea. The aqueous solutions of $\mathrm{Zn}\left(\mathrm{NO}_{3}\right)_{2}$ and $\mathrm{CO}\left(\mathrm{NH}_{2}\right)_{2}$ was heated at a temperature of $363 \mathrm{~K}$ and stirred for $24 \mathrm{~h}$. The resulting precipitation was washed, dried at $383 \mathrm{~K}$, and calcined at $773 \mathrm{~K}$ for $2 \mathrm{~h}$.

Nanocrystalline $\mathrm{TiO}_{2}$ particles were synthesized by the hydrolysis of titanium isopropoxide [17] using a modified method [18]. Synthesis was carried out under vigorous stirring in excess of 2-propanol. The reaction mixture was gradually heated to $358 \mathrm{~K}$ with addition of deionized water to eliminate the intermediate gelation process. The resulting solid precipitation was filtered, dried in the air at $358 \mathrm{~K}$, and calcined at $773 \mathrm{~K}$.

As a reference sample used a titanium dioxide Degussa P25 $\left(\mathrm{TiO}_{2}\right.$ P25), obtained by high-temperature gas-phase oxidation of titanium tetrachloride vapors [19].

2.3. Photocatalyst Characterizations Techniques. In order to characterize the powders instrument measurements were performed with X-ray diffraction (diffractometer DRON $3 \mathrm{M}$ generating $\operatorname{CoK} \alpha_{1}(\lambda=0.17902 \mathrm{~nm})$ radiation), diffuse reflectance UV-Vis spectroscopy (Shimadzu UV-2405 spectrometer with integrated sphere ISR-2200 and $\mathrm{BaSO}_{4}$ as the reference), and $\mathrm{N}_{2}$-adsorption measurements (Micromeritics ASAP vacuum device 2010).

2.4. Photocatalytic Reactor and Experimental Procedure. Photocatalytic degradation of phenol was carried out in a $0.5 \mathrm{~L}$ quartz reactor with a jacket under air bubbling (velocity $50 \mathrm{~mL} \cdot \mathrm{min}^{-1}$ ) and temperature from $293 \mathrm{~K}$ to $323 \mathrm{~K}$. The reaction mixture was agitated with a magnetic stirrer $\left(800 \mathrm{rpm} \cdot \mathrm{min}^{-1}\right)$. The concentrations of phenol and catalyst were $0.532 \mathrm{mM}$ and $1 \mathrm{~g} \cdot \mathrm{L}^{-1}$, respectively. Low-pressure mercury lamp DRB-8 submerged in a quartz casing used as a UV-radiation source with a maximum emission output at $254 \mathrm{~nm}$. Reaction time was 3 hours. The separation of reaction mixture was performed by centrifugation. The effectiveness of photocatalytic process was evaluated relative to the photolysis carried out under similar conditions without catalyst usage. The phenol conversion was determined by the aromatic content recorded by the absorbance of the solution at $270 \mathrm{~nm}\left(C_{270}\right)$ with a Shimadzu UV-2405 spectrometer and concentration of total organic carbon $\left(C_{\mathrm{TOC}}\right)$ measured by Shimadzu TOC-VCSN analyzer.

\section{Results and Discussion}

3.1. Photocatalysts Characterization. Figure 2 presents the Xray powder diffraction patterns of the synthesized semiconductor oxides and reference sample $\mathrm{TiO}_{2}$ P25.

The XRD pattern of $\mathrm{Fe}_{2} \mathrm{O}_{3}$ sample shows that all basal reflections in the range of Bragg angles $(2 \theta)$ from 10 to 80 characterize of isomorphic hematite phase $\left(\alpha-\mathrm{Fe}_{2} \mathrm{O}_{3}\right)$, corresponding to the orthorhombic crystal system (JCPDS No. 791741).

Investigation of the crystal structure of $\mathrm{WO}_{3}$ confirms the presence of hexagonal phase (R6/mmm), JCPDS No. 331387). Low peak-height indicates the weakly crystallized structure.

The X-ray diffraction pattern of the prepared $\mathrm{TiO}_{2}$ sample is presented basal reflections (at around $2 \Theta 25.4,44.2$, and 56.4) corresponding to the titanium dioxide anatase phase [17].

As is known, after calcination for $2 \mathrm{~h} \mathrm{TiO}_{2} \mathrm{P} 25$ is a mixture of anatase and rutile phase ( 82 and $18 \%$, resp.) [19].

XRD analysis of the synthesized $\mathrm{ZnO}$ shows strong and high peaks indicating the high purity and crystallinity. 


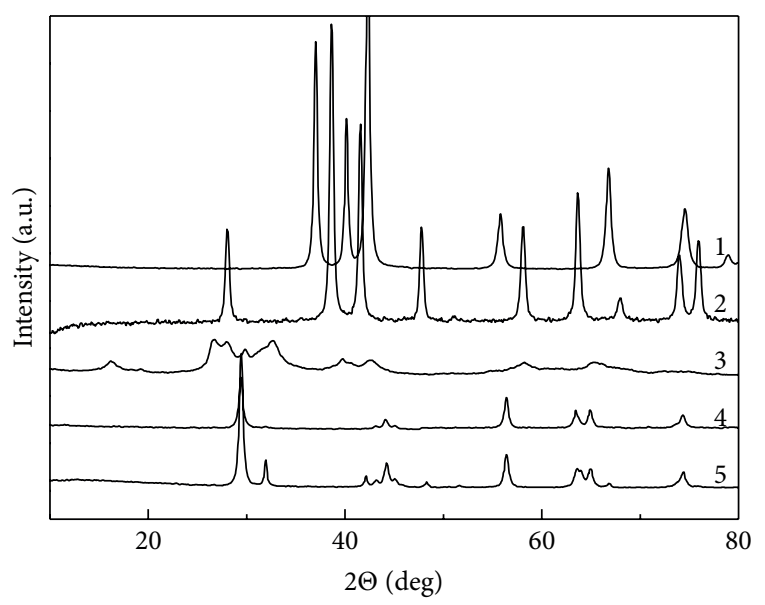

FIgURE 2: X-ray diffraction patterns of the semiconductor oxides: $1-\mathrm{ZnO} ; 2-\alpha-\mathrm{Fe}_{2} \mathrm{O}_{3} ; 3-\mathrm{WO}_{3} ; 4-\mathrm{TiO}_{2} ; 5-\mathrm{TiO}_{2}$ P25.

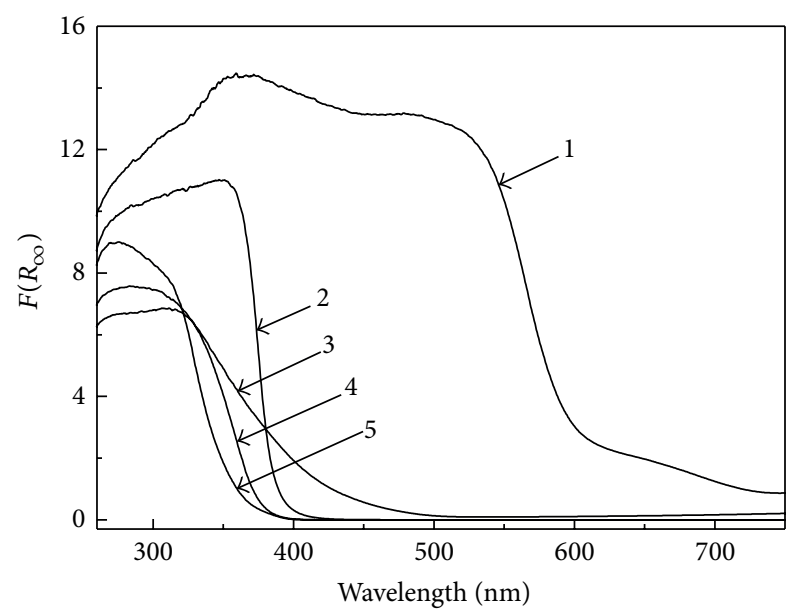

FIGURE 3: Diffuse reflectance spectra of semiconductor oxides: 1$\alpha-\mathrm{F}_{2} \mathrm{O} ; 2-\mathrm{ZnO} ; 3-\mathrm{WO}_{3} ; 4-\mathrm{TiO}_{2} ; 5-\mathrm{TiO}_{2} \mathrm{P} 25$.

Location of the basal reflections confirms hexagonal structure of $\mathrm{ZnO}$ (JCPDS No. 80-0075).

Diffuse reflectance spectroscopy allows obtaining information about light absorption range and band gap of the semiconductor [20]. Figure 3 depicts diffuse reflectance spectra of the synthesized materials converted in accordance to the Kubelka-Munk function. The energy band gap $\left(E_{g}, e V\right)$ is determined by extrapolating of the onset of the rising part to $x$-axis $\left(\lambda_{g}, \mathrm{~nm}\right)$ of the plots by the dotted line and calculation by the following equation (see [21]):

$$
E_{g}=\frac{1240}{\lambda_{g}}
$$

It can be clearly seen from Figure 3 that the radiation absorption by $\mathrm{WO}_{3}$ sample begins in the visible range at $500 \mathrm{~nm}$. The band gap of $\mathrm{WO}_{3}$ is $2.55 \mathrm{eV}$ which is consistent with literature data [22].

The optical absorption spectrum of the $\mathrm{ZnO}$ sample is represented by a broad and intense band and characterized by
TABLE 1: Physical and chemical characteristics of the investigated semiconductor oxides.

\begin{tabular}{lcccc}
\hline Sample & $\begin{array}{c}S_{\mathrm{BET}} \\
\left(\mathrm{m}^{2} \cdot \mathrm{g}^{-1}\right)\end{array}$ & $\begin{array}{c}V_{\text {micropore }} \\
\left(\mathrm{cm}^{3} \cdot \mathrm{g}^{-1}\right)\end{array}$ & $E_{g},(\mathrm{eV})$ & $L^{\mathrm{a}},(\mathrm{nm})$ \\
\hline$\alpha-\mathrm{Fe}_{2} \mathrm{O}_{3}$ & 25,7 & 0,18 & 2,0 & 2000 \\
$\mathrm{WO}_{3}$ & 50 & 0,005 & 2,55 & 20 \\
$\mathrm{ZnO}$ & 41 & $-{ }^{\mathrm{d}}$ & 3,23 & 3000 \\
$\mathrm{TiO}_{2}$ & 45,3 & 0,1 & 3,43 & $5-7$ \\
$\mathrm{TiO}_{2} \mathrm{P}^{2} 5^{\mathrm{b}}$ & 52 & 0,18 & 3,23 & 28 \\
\hline
\end{tabular}

$S_{\mathrm{BET}}$ : specific surface area data obtained from the BET-model.

$V_{\text {micropore }}$ micropore volume data calculated by deBoer's $t$-plot method.

$E_{g}$ : energy band gap.

$L$ : linear particle size.

- : not determined.

${ }^{\mathrm{a}, \mathrm{b}}$ Published data.

a sharp increase of absorption at $400 \mathrm{~nm}$ and a slight decrease at shorter wavelengths.

In the DRS of the $\mathrm{TiO}_{2}$ P25 and synthesized $\mathrm{TiO}_{2}$ powder the drastic increasing of the light absorption at $\lambda=$ $380 \mathrm{~nm}$ corresponding to the energy band gap of pure anatase $(\sim 3.2 \mathrm{eV})$ can be noted [23].

The surface area and micropore volume of the synthesized materials are defined with nitrogen adsorption-desorption isotherm. Surface parameters and the energy band gap of the SO are shown in Table 1. It is known that $\alpha-\mathrm{Fe}_{2} \mathrm{O}_{3}$ and $\mathrm{ZnO}$ particles obtained by a sol-gel method by means of thermoinitiated decomposition of urea have a relatively large size (2000 and $3000 \mathrm{~nm}$, resp.) $[15,16]$ and a low specific surface area. The synthesized $\mathrm{WO}_{3}$ sample has a high specific surface area with a small volume share of the micropores. Despite the high dispersion of the synthesized $\mathrm{TiO}_{2}$ sample, its specific surface area is less than that of the $\mathrm{TiO}_{2} \mathrm{P} 25$ sample because of lower specific volume of the micropores.

3.2. Photodegradation of Phenol. The results of photolysis and photocatalytic degradation study of phenol using prepared semiconductor oxides and $\mathrm{TiO}_{2} \mathrm{P} 25$ samples are shown in Figure 4.

During the photolysis of phenol under UV-C irradiation the appearance of light brown color and increase of the optical density of analyzed solution are observed, which can be explained by the formation of colored intermediates: benzoquinone, hydroquinone, and catechol [6]. Incomplete oxidation of phenol confirmed its low mineralization (22\%, Figure 4), and indicates necessity of catalytic method usage.

The study of phenol conversion dependence on the $\mathrm{SO}$ nature found that the least active are the $\alpha-\mathrm{Fe}_{2} \mathrm{O}_{3}$ and $\mathrm{WO}_{3}$ samples (mineralization is $14 \%$ and $26 \%$ resp.). The increase of optical density of the solution after photocatalysis suggests the formation of colored intermediates. The phenol conversion using $\mathrm{ZnO}$ powder was $24 \%$ of aromatic content and $52 \%$ of $\mathrm{TOC}$. $\mathrm{TiO}_{2}$ samples showed the highest activity. Application of synthesized sample $\mathrm{TiO}_{2}$ leads to aromatic content of $79 \%$ and TOC of $85 \%$ removal. These results are similar to the activity of $\mathrm{TiO}_{2} \mathrm{P} 25$ sample. 


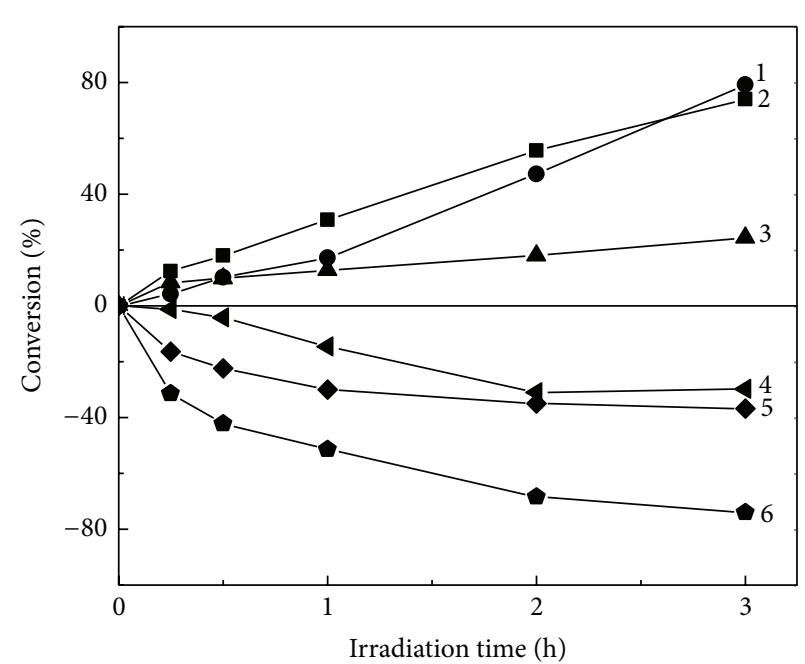

(a)

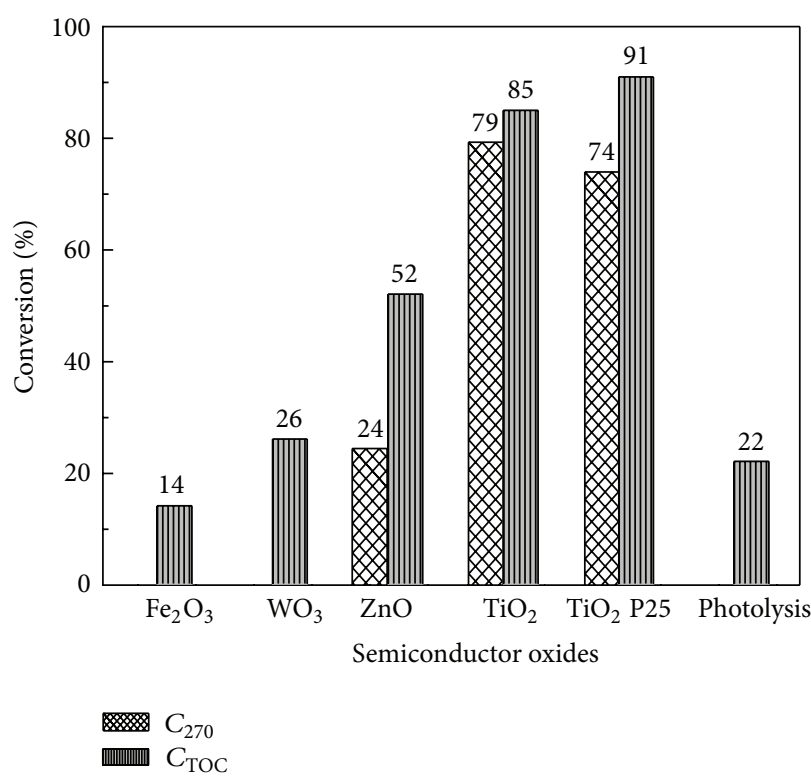

(b)

FIGURE 4: Effectiveness of investigated semiconductor oxides in photocatalytic phenol degradation. Experimental conditions: initial phenol concentration $=0.536 \mathrm{mM}$; catalyst concentration $=0.1 \mathrm{~g} \cdot \mathrm{L}^{-1} ; \mathrm{pH}=5.9 ; T=303 \mathrm{~K}$. (a) Variations of $C_{270}$ values during phenol photodegradation: $1-\mathrm{TiO}_{2} \mathrm{P} 25 ; 2-\mathrm{TiO}_{2} ; 3-\mathrm{ZnO} ; 4-\mathrm{WO}_{3} ; 5-$ photolysis; $6-\alpha-\mathrm{Fe}_{2} \mathrm{O}_{3} ;$ (b) $C_{270}$ and $C_{\mathrm{TOC}}$ values of phenol solution after reaction.

TABLE 2: Degree of substrate conversion $\left(C_{270}\right.$ and $\left.C_{\mathrm{TOC}}\right)$ and total $(A)$ and specific catalytic activity $(a)$ of investigated $\mathrm{SO}$ in the reaction of phenol photocatalytic degradation in water.

\begin{tabular}{lcccc}
\hline Sample & $C_{270}, \%$ & $C_{\text {TOC }}, \%$ & $\begin{array}{c}A \cdot 10^{-8}, \\
\mathrm{M} \cdot \mathrm{g}^{-1} \cdot \mathrm{sec}^{-1}\end{array}$ & $\begin{array}{c}a \cdot 10^{-11}, \\
\mathrm{M} \cdot \mathrm{m}^{-2} \cdot \mathrm{sec}^{-1}\end{array}$ \\
\hline$\alpha-\mathrm{Fe}_{2} \mathrm{O}_{3}$ & - & 14 & 0,7 & 0,3 \\
$\mathrm{WO}_{3}$ & - & 26 & 1,3 & 2,6 \\
$\mathrm{ZnO}$ & 24 & 52 & 2,6 & 6,3 \\
$\mathrm{TiO}_{2}$ & 79 & 85 & 4,2 & 9,2 \\
$\mathrm{TiO}_{2} \mathrm{P} 25$ & 74 & 91 & 4,5 & 8,6
\end{tabular}

-: the reduction of optical density does not occur.

Table 2 shows the phenol aromatic content $\left(C_{270}\right)$ and TOC $\left(C_{\mathrm{TOC}}\right)$ conversion dependence on the $\mathrm{SO}$ nature, as well as the total $(A)$ and specific $(a)$ catalytic activity of investigated SO, calculated by the following equation (see [24]):

$$
\begin{gathered}
A=\frac{C_{\mathrm{TOC}}}{\tau \cdot m}, \\
a=\frac{A}{S_{\mathrm{BET}} \cdot C_{c}},
\end{gathered}
$$

where $\tau$ is the reaction time (sec); $\mathrm{m}$ is the mass of catalyst (g); $S_{\mathrm{BET}}$ is the specific surface area data obtained from the BET-model $\left(\mathrm{m}^{2} \cdot \mathrm{g}^{-1}\right) ; C_{c}$ is the catalyst concentration $\left(\mathrm{g} \cdot \mathrm{L}^{-1}\right)$.

The use of $\alpha-\mathrm{Fe}_{2} \mathrm{O}_{3}$ and $\mathrm{WO}_{3}$ samples in the reaction of phenol photocatalytic degradation leads to increase of solution optical density through the formation of colored intermediates. These oxides showed the lowest activity because of their low redox potential (Figure 1). In contrast, the usage of $\mathrm{ZnO}, \mathrm{TiO}_{2}$, and $\mathrm{TiO}_{2} \mathrm{P} 25$ samples reduces aromatic content and total organic carbon. $\mathrm{ZnO}$ sample takes an intermediate position among the studied semiconductor oxides by the values of the total and the specific catalytic activity. $\mathrm{TiO}_{2}$ sample synthesized by a modified sol-gel method has a higher specific activity compared with $\mathrm{TiO}_{2}$ P25 (9.2 and $8.6 \mathrm{M} \cdot \mathrm{m}^{-2} \cdot \mathrm{s}^{-1}$, resp.) due to predomination of crystal modification of anatase which compared with rutile has a high surface concentration of active catalytic centers [25].

Investigation of the degradation process of phenol was followed by $\mathrm{pH}$ measuring of the reaction mixture. In all cases the $\mathrm{pH}$ decrease is associated with the formation of shortchain fatty acids [26].

It is found that the specific activity of SO in the reaction of phenol photocatalytic degradation changes in a number of $\alpha-\mathrm{Fe}_{2} \mathrm{O}_{3}<\mathrm{WO}_{3}<\mathrm{ZnO}<\mathrm{TiO}_{2} \mathrm{P} 25<\mathrm{TiO}_{2}$. Therefore, the determination of optimal conditions for phenol photocatalytic oxidation was carried out using the $\mathrm{TiO}_{2}$ sample synthesized by the modified sol-gel method.

The influence of the catalyst concentration on the phenol conversion in water (Figure 5) showed a maximum efficiency at a concentration of $1 \mathrm{~g} \cdot \mathrm{L}^{-1}$. Lower and higher concentrations of $\mathrm{TiO}_{2}$ sample led to decrease of conversion degree associated with reduction of active sites number and radiation screening effect of $\mathrm{TiO}_{2}$ particles excess [27].

Effect of initial phenol concentration on its conversion in water is shown on Figure 6. Rise of phenol concentration from 0.266 to $1.596 \mathrm{mM}$ leads to decrease in the conversion degree for two indicators that can be attributed to an increase in the absorption of radiation by phenol molecules more than 


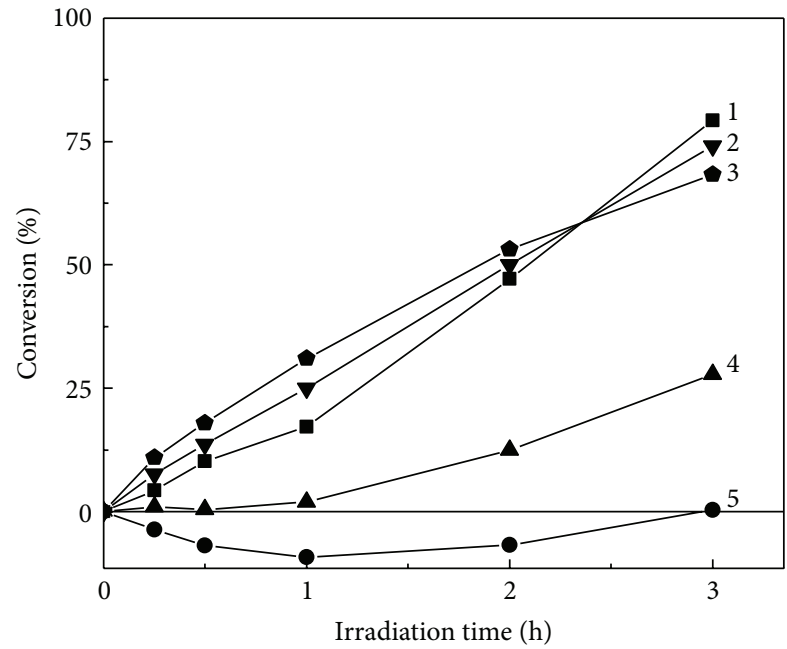

(a)

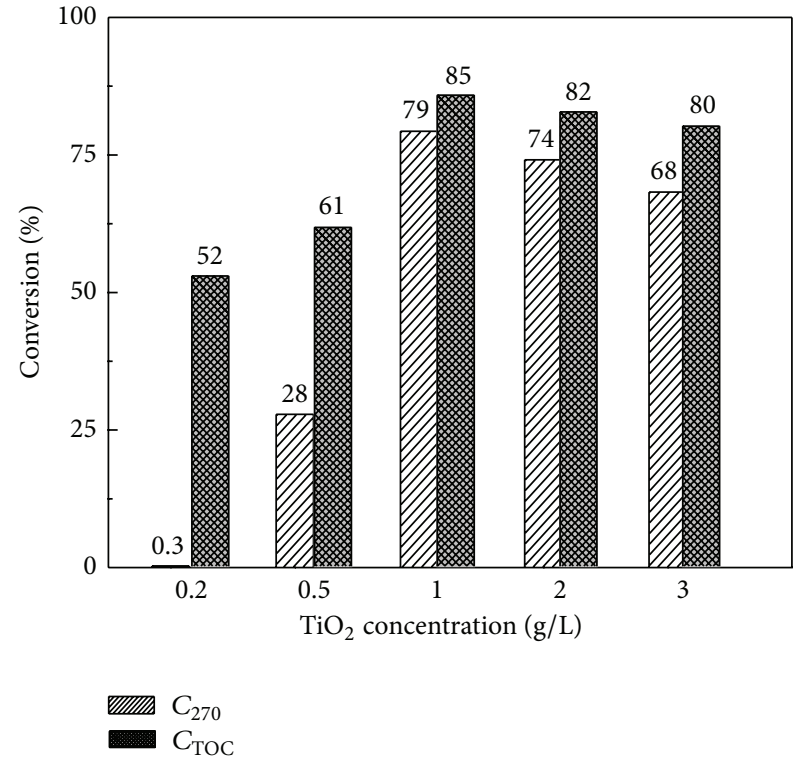

(b)

FIgURE 5: Effect of $\mathrm{TiO}_{2}$ concentration on phenol conversion. Experimental conditions: initial phenol concentration $=0.536 \mathrm{mM}$; $\mathrm{pH}=5.9$; $T=303 \mathrm{~K}$. (a) Variations of $C_{270}$ values during phenol photodegradation: $1-1 \mathrm{~g} \cdot \mathrm{L}^{-1} ; 2-2 \mathrm{~g} \cdot \mathrm{L}^{-1} ; 3-3 \mathrm{~g} \cdot \mathrm{L}^{-1}, 4-0.5 \mathrm{~g} \cdot \mathrm{L}^{-1}, 5-0.2 \mathrm{~g} \cdot \mathrm{L}^{-1} ;(\mathrm{b}) C_{270}$ and $C_{\mathrm{TOC}}$ values of phenol solution after reaction.

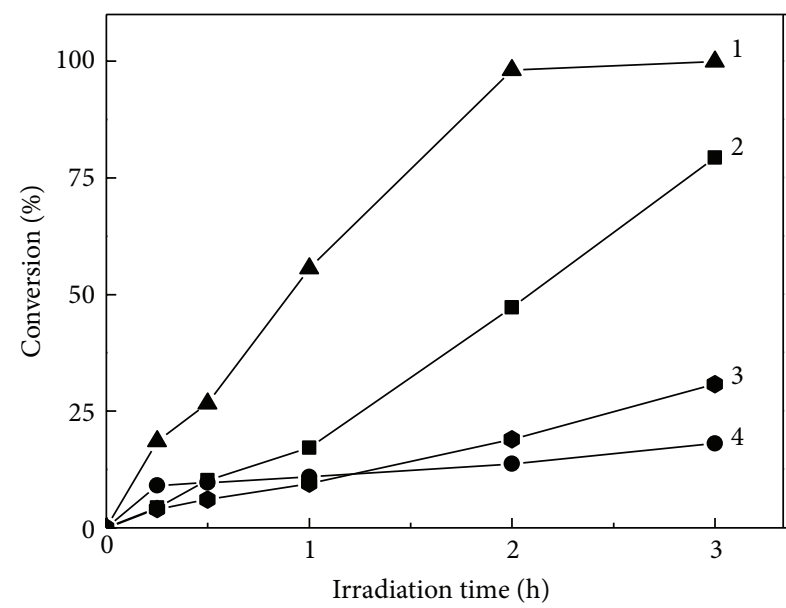

(a)

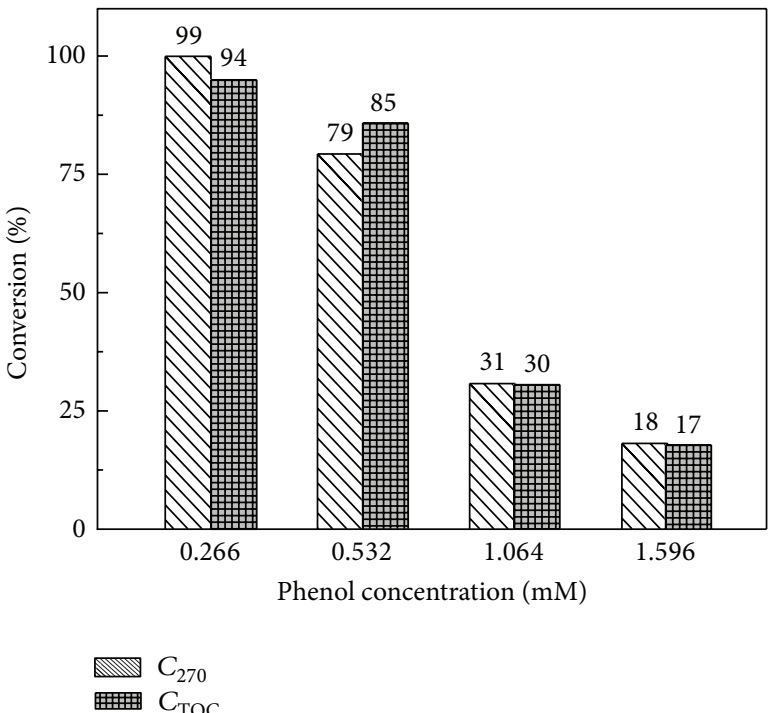

(b)

FIGURE 6: Effect of initial phenol concentration on its conversion. Experimental conditions: $\mathrm{TiO}_{2}$ concentration $=0.1 \mathrm{~g} \cdot \mathrm{L}^{-1} ; \mathrm{pH}=5.9 ; \mathrm{T}=$ $303 \mathrm{~K}$. (a) Variations of $C_{270}$ values during phenol photodegradation: $1-0.266 \mathrm{mM} ; 2-0.532 \mathrm{mM} ; 3-1.064 \mathrm{mM} ; 4-1.596 \mathrm{mM}$; (b) $C_{270}$ and $C_{\mathrm{TOC}}$ values of phenol solution after reaction.

that of the catalyst particles and the increase of competitive adsorption of ${ }^{-} \mathrm{OH}$ on the same surface site of catalyst [27].

Phenol photodegradation efficiency largely depends on the $\mathrm{pH}$ value. Studies showed that aromatic content degradation of phenol and reduction of TOC in an acidic medium
$(\mathrm{pH}=3)$ are significantly low $(37 \%$ and $34 \%$, resp.) in comparison with in alkaline medium $(\mathrm{pH}=8)(72 \%$ and $56 \%$, resp.). Effect of $\mathrm{pH}$ on the photodegradation degree of phenol can be caused by changing in the surface charge of semiconductor, phenol chemical transformations in the 


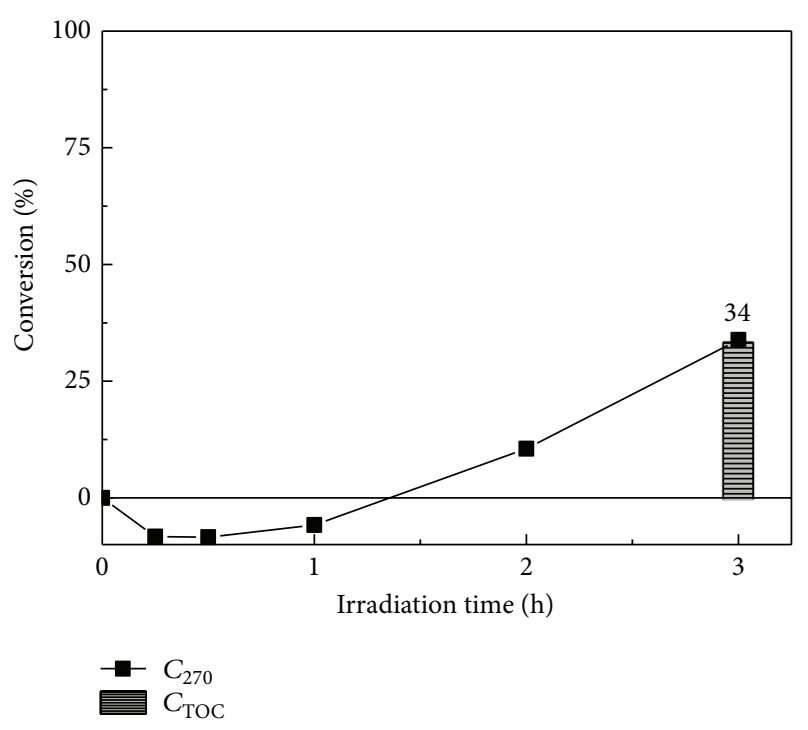

FIGURE 7: The photocatalytic conversion of phenol in tap water using synthesized $\mathrm{TiO}_{2}$ samples.

solution, and carbonate ions formation which are effective scavengers of $\mathrm{OH}^{*}$ radicals [27].

The study of photocatalytic phenol conversion dependence on reaction temperature was carried out in range from 293 to $323 \mathrm{~K}$. Maximum conversion (96\% of aromaticity and $86 \%$ of TOC conversion) in temperature range $303-313 \mathrm{~K}$ was observed.

The efficiency evaluation of the synthesized $\mathrm{TiO}_{2}$ sample in the real conditions was carried out in Kiev tap water [28], Ukraine (Figure 7). The experimental conditions were the same as in the case of semiconductor oxides activity determination. At the beginning of the reaction rise of solution optical density takes place (Figure 7) which can be explained by the formation of intermediates. Further oxidation leads to the destruction of aromatic content and increase of conversion.

\section{Conclusions}

The specific activity of investigated semiconductor oxides in the reaction of phenol photocatalytic degradation changes in a number of $\alpha-\mathrm{Fe}_{2} \mathrm{O}_{3}<\mathrm{WO}_{3}<\mathrm{ZnO}<\mathrm{TiO}_{2} \mathrm{P} 25<\mathrm{TiO}_{2}$. It is shown that titanium dioxide synthesized by the modified solgel method is the most effective photocatalyst in this process. The resulting $\mathrm{TiO}_{2}$ has a higher specific catalytic activity than industrial sample $\mathrm{TiO}_{2} \mathrm{P} 25$. The maximum efficiency of the catalyst usage is achieved in 303-313 K temperature range at $\mathrm{TiO}_{2}$ concentration of $1 \mathrm{~g} \cdot \mathrm{L}^{-1}$, phenol concentration of $0.532 \mathrm{mM}$, and neutral $\mathrm{pH}$. The presence of electrolytes reduces the efficiency of the process.

\section{Conflict of Interests}

The authors declared that there is no conflict of interests.

\section{References}

[1] U. I. Gaya and A. H. Abdullah, "Heterogeneous photocatalytic degradation of organic contaminants over titanium dioxide: a review of fundamentals, progress and problems," Journal of Photochemistry and Photobiology C, vol. 9, no. 1, pp. 1-12, 2008.

[2] V. V. Goncharuk, Environmental Aspects of Modern Technologies Protect the Aquatic Environment, Naukova dumka, Kiev, Ukraine, 2005.

[3] M. Anpo, "Utilization of $\mathrm{TiO}_{2}$ photocatalysts in green chemistry," Pure and Applied Chemistry, vol. 72, no. 7, pp. 1265-1270, 2000.

[4] D. Chen and L. Gao, "A facile route for high-throughput formation of single-crystal $\alpha-\mathrm{Fe}_{2} \mathrm{O}_{3}$ nanodisks in aqueous solutions of Tween 80 and triblock copolymer," Chemical Physics Letters, vol. 395, no. 4-6, pp. 316-320, 2004.

[5] V. V. Goncharuk, "Photocatalytic destructive oxidation of organic compounds in aqueous media," Chemistry for Sustainable Development, vol. 5, pp. 345-355, 1997.

[6] S. K. Pardeshi and A. B. Patil, "A simple route for photocatalytic degradation of phenol in aqueous zinc oxide suspension using solar energy," Solar Energy, vol. 82, no. 8, pp. 700-705, 2008.

[7] N. M. Soboleva, A. A. Nosovich, and V. V. Goncharuk, "The heterogenic photocatalysis in water treatment processes," Journal of Water Chemistry and Technology, vol. 29, no. 2, pp. 72-89, 2007.

[8] L. E. Sheinkman and D. V. Dergunov, "Protection of surface and groundwater from phenols pollution in underground coal mining," in Proceedings of the International Scientific and Practical Conference Science and Technology in the Modern World, 2011.

[9] A. O. Samsoni-Todorov, E. A. Rolya, V. M. Kochkodan, and V. V. Goncharuk, "Photocatalytic destruction of phenol in water in the presence of cerium hydroperoxide," Journal of Water Chemistry and Technology, vol. 30, no. 3, pp. 151-156, 2008.

[10] A. Memar, W. R. W. Daud, S. Hosseini, E. Eftekhari, and L. J. Minggu, "Study on photocurrent of bilayers photoanodes using different combination of $\mathrm{WO}_{3}$ and $\mathrm{Fe}_{2} \mathrm{O}_{3}$," Solar Energy, vol. 84, no. 8, pp. 1538-1544, 2010.

[11] Y. J. Jang, C. Simer, and T. Ohm, "Comparison of zinc oxide nanoparticles and its nano-crystalline particles on the photocatalytic degradation of methylene blue," Materials Research Bulletin, vol. 41, no. 1, pp. 67-77, 2006.

[12] M. Grätzel, "Photoelectrochemical cells," Nature, vol. 414, no. 6861, pp. 338-344, 2001.

[13] A. Martínez-de la Cruz, D. S. Martínez, and E. L. Cuéllar, "Synthesis and characterization of $\mathrm{WO}_{3}$ nanoparticles prepared by the precipitation method: evaluation of photocatalytic activity under vis-irradiation," Solid State Sciences, vol. 12, no. 1, pp. 8894, 2010.

[14] M. Crişan, A. Brǎileanu, M. Rǎileanu et al., "Sol-gel S-doped $\mathrm{TiO}_{2}$ materials for environmental protection," Journal of NonCrystalline Solids, vol. 354, no. 2-9, pp. 705-711, 2008.

[15] W. Yan, H. Fan, Y. Zhai, C. Yang, P. Ren, and L. Huang, "Low temperature solution-based synthesis of porous flowerlike $\alpha-\mathrm{Fe}_{2} \mathrm{O}_{3}$ superstructures and their excellent gas-sensing properties," Sensors and Actuators B, vol. 160, no. 1, pp. 13721379, 2011.

[16] D. Li and H. Haneda, "Morphologies of zinc oxide particles and their effects on photocatalysis," Chemosphere, vol. 51, no. 2, pp. 129-137, 2003.

[17] K. I. Gnanasekar, V. Subramanian, J. Robinson, J. C. Jiang, F. E. Posey, and B. Rambabu, "Direct conversion of $\mathrm{TiO}_{2}$ sol to 
nanocrystalline anatase at $85^{\circ} \mathrm{C}$," Journal of Materials Research, vol. 17, no. 6, pp. 1507-1512, 2002.

[18] V. V. Goncharuk, M. V. Sychev, I. V. Stolyarova, R. V. Prihod'ko, I. O. Ledenev, and A. V. Lozovski, "MPK 7 B01 J21/00, 23/48, C $01 \mathrm{~F} 1 / 70$, The catalyst for water purification from nitrate ions, the method of its preparation and water purification," Patent of Ukraine 7, Bulletin, 2006.

[19] A. V. Tarasov, Metallurgy of Titanium, Akademkniga, Moscow, Russia, 2003.

[20] A. Zecchina, G. Spoto, S. Bordiga et al., "Framework and extraframework $\mathrm{Ti}$ in Titanium-Silicalite: investigation by means of physical methods," Studies in Surface Science and Catalysis, vol. 69, pp. 251-258, 1991.

[21] T. Sreethawong, Y. Suzuki, and S. Yoshikawa, "Synthesis, characterization, and photocatalytic activity for hydrogen evolution of nanocrystalline mesoporous titania prepared by surfactantassisted templating sol-gel process," Journal of Solid State Chemistry, vol. 178, no. 1, pp. 329-338, 2005.

[22] G. R. Bamwenda and H. Arakawa, "The visible light induced photocatalytic activity of tungsten trioxide powders," Applied Catalysis A, vol. 210, no. 1-2, pp. 181-191, 2001.

[23] M. Yan, F. Chen, J. Zhang, and M. Anpo, "Preparation of controllable crystalline titania and study on the photocatalytic properties," Journal of Physical Chemistry B, vol. 109, no. 18, pp. 8673-8678, 2005.

[24] Y. I. Gerasimov, "Course of Physical Chemistry," Chemistry, vol. 2, article 289, 1973.

[25] M. I. Litter, "Heterogeneous photocatalysis: transition metal ions in photocatalytic systems," Applied Catalysis B, vol. 23, no. 2-3, pp. 89-114, 1999.

[26] S. Ahmed, M. G. Rasul, W. N. Martens, R. Brown, and M. A. Hashib, "Heterogeneous photocatalytic degradation of phenols in wastewater: a review on current status and developments," Desalination, vol. 261, no. 1-2, pp. 3-18, 2010.

[27] N. Kashif and F. Ouyang, "Parameters effect on heterogeneous photocatalysed degradation of phenol in aqueous dispersion of $\mathrm{TiO}_{2}$," Journal of Environmental Sciences, vol. 21, no. 4, pp. 527533, 2009.

[28] V. V. Goncharuk, Kyiv Pump Room. The Quality of Artesian Water, vol. 55, Geoprint, 2003. 

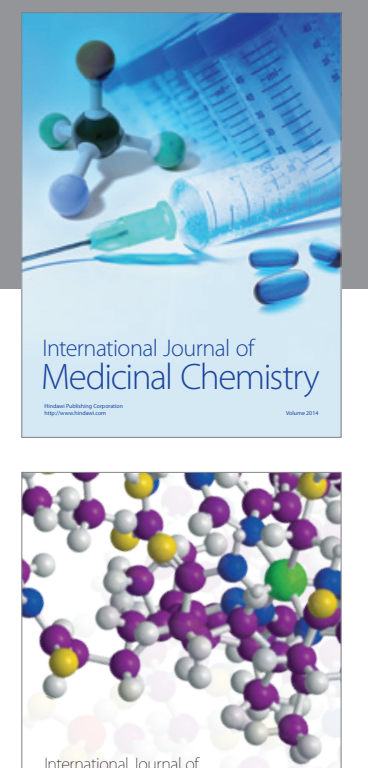

\section{Carbohydrate} Chemistry

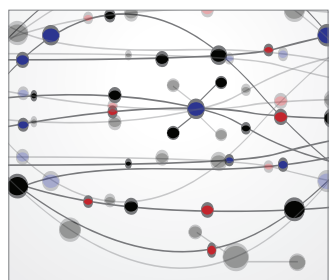

The Scientific World Journal
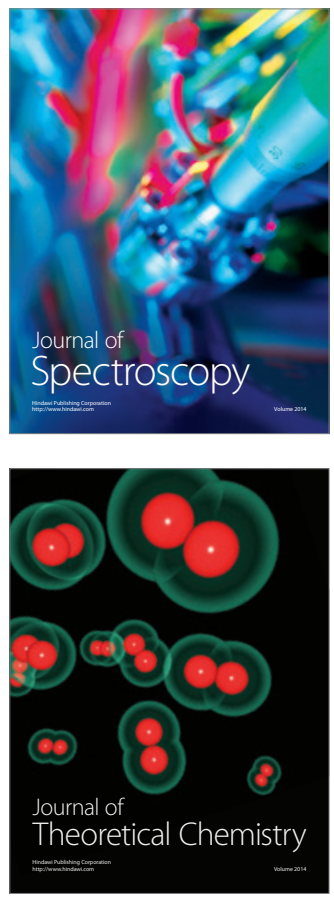
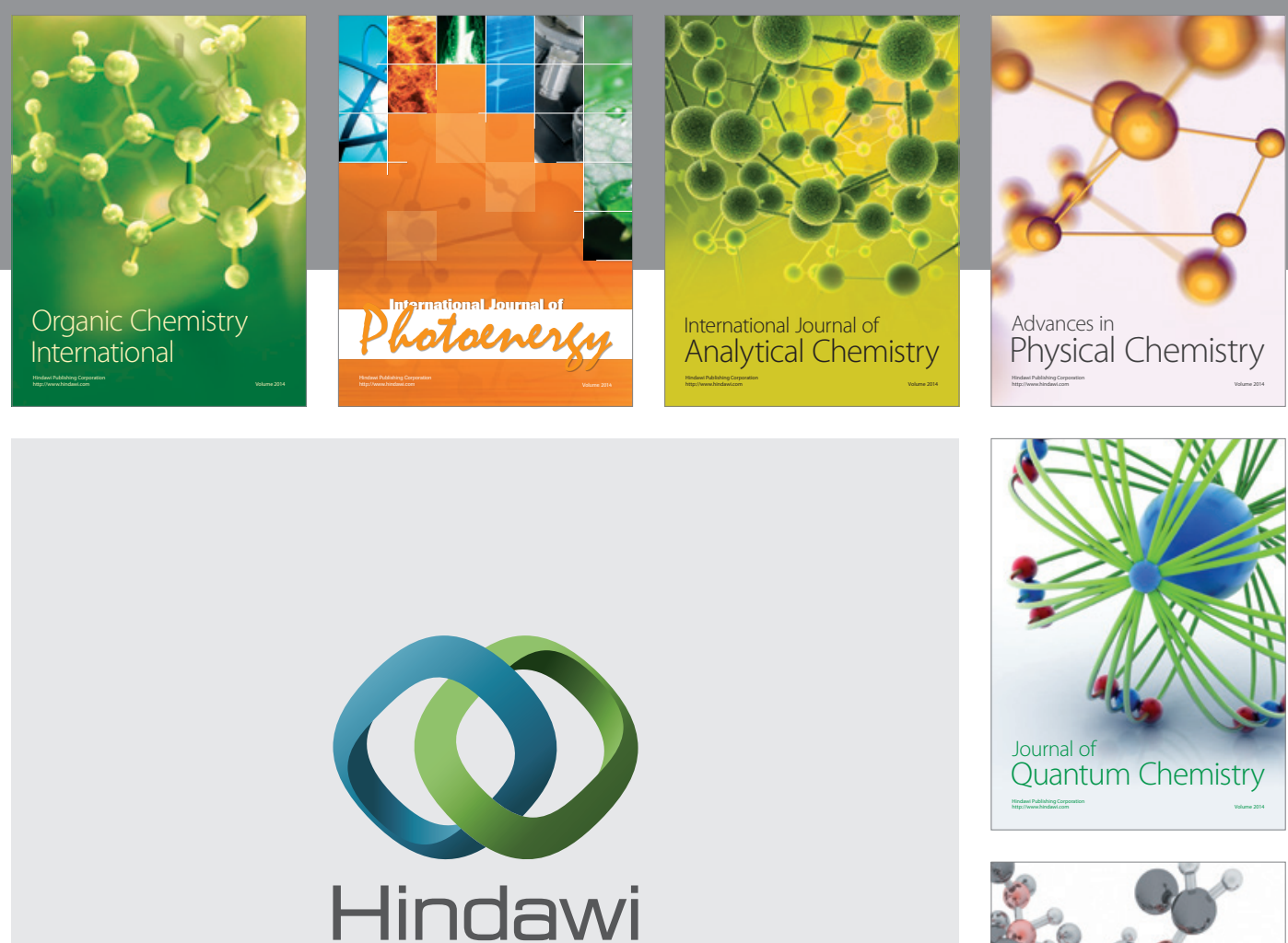

Submit your manuscripts at

http://www.hindawi.com

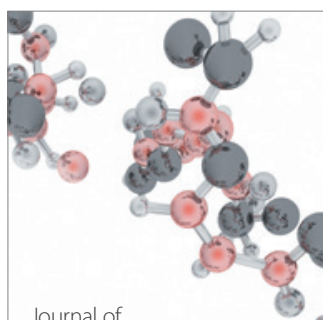

Analytical Methods

in Chemistry

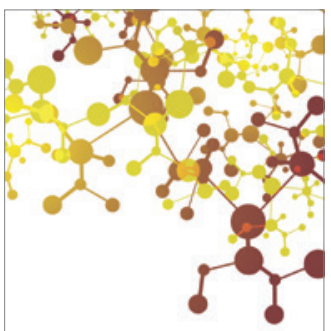

Journal of

Applied Chemistry

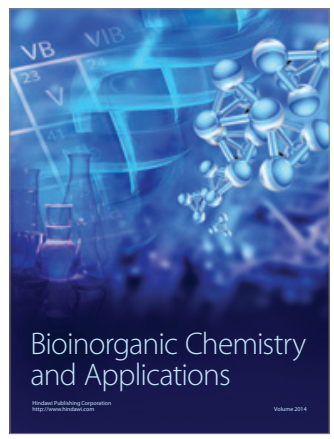

Inorganic Chemistry
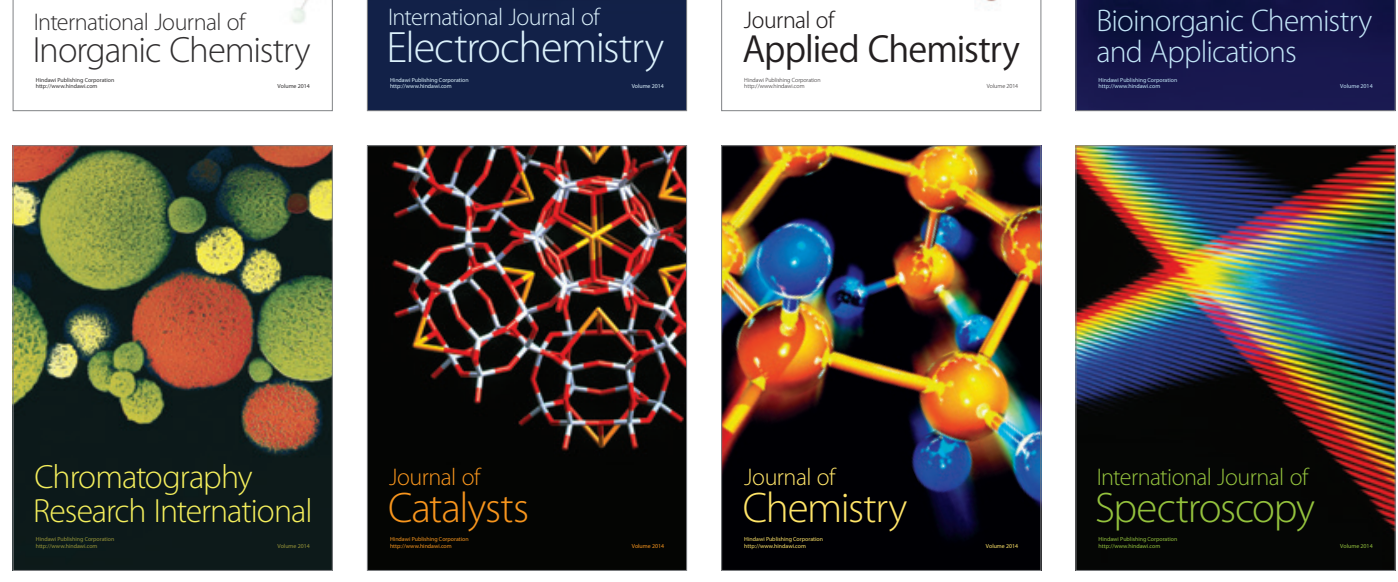